\title{
Escrever (sobre) os afetos: a escrita intima de Annie Ernaux
}

Writing (on) affects: Annie Ernaux's inner writing

Leila de Aguiar Costa

UNIFESP

DOI: $h t t p: / / d x . d o i . o r g / 10.5902 / 2176148531546$

Resumo: Os romances da francesa Annie Ernaux, que ela mesma inscreve nas fileiras do parecem construir toda uma cenografia dos afetos que põe o Eu em diálogo com o Outro. $\mathrm{O}$ movimento dos afetos, que perpassa obras como La place (1983), Une femme (1987) e Journal du dehors (1993), quaisquer sejam seus fluxos - do interior para o exterior, do exterior para o interior -, encena a constituição mesma do sujeito, indelevelmente inscrita em uma comunidade, familiar, fraternal, coletiva. A proposta aqui é, pois, percorrer essas três narrativas procurando nelas reconhecer uma particular escrita do(s) afeto(s).

Palavras-chave: Afeto(s). Escrita de si. Comunidade.

Abstract: The novels of the French Annie Ernaux, considered by the literary critic as inscribed in the contemporary genre "autofiction", seem to construct a whole set of affections that puts the I in dialogue with the Other. The movement of affections that runs through works such as La place (1983), Une femme (1987) and Journal du dehors (1993), whatever their fluxes - from the interior to the exterior, from the exterior to the interior - enact the very constitution of the subject, indelibly inscribed in a community, family, fraternal, collective. The proposal here is, therefore, to go through these four autofictions looking for in them to recognize a particular writing of the affection (s).

Keywords: Affect(s). Self-writing. Autofiction. Community 
O inferno não são os outros, pequena Halla. Eles são o paraíso, porque um homem sozinho é apenas um animal. A humanidade começa nos que te rodeiam, e não exatamente em ti. Ser-se a pessoa implica a tua mãe, as nossas pessoas, um desconhecido ou a sua expectativa. Sem ninguém no presente nem no futuro, o indivíduo pensa tão sem razão quanto pensam os peixes.

Valter Hugo Mãe. O paraíso são os outros.

Leila

de Aguiar

Costa

Do novelo emaranhado da memória, da escuridão dos nós cegos, puxo um fio que me aparece solto. / Devagar o liberto, de medo que se desfaça entre os dedos. / É um fio longo, verde e azul, com cheiro de limos, e tem a macieza quente do lodo vivo. / É um rio. / corre-me nas mãos, agora molhadas. / Toda a água me passa entre as palmas abertas, e de repente não sei se as águas nascem de mim, ou para mim fluem. / Continuo a puxar, não já memória apenas, mas o próprio corpo do rio. / Sobre a minha pele navegam barcos, e sou também os barcos e o céu que os cobre, e os altos choupos que vagarosamente deslizam sobre a película luminosa dos olhos. / Nadam-me peixes no sangue e oscilam entre duas águas como os apelos imprecisos da memória. José Saramago. As pequenas memórias

Il n'y a pas de vraie mémoire de soi.

Annie Ernaux. La honte

\section{O Eu não é o Si...}

As três epígrafes de abertura - que aqui têm igualmente valor de moldura - insinuam o que se entenderá pela escrita do(s) afeto(s) de Annie Ernaux. Mais do que autonomia do "Eu", prova da transcendência do sujeito, de seu poder, de sua identidade, a narrativa de si que se dedica ao registro do(s) afeto(s) parece unicamente fazer sentido se em contato com outras narrativas, com os traços deixados pelo corpo e pelas palavras de Outro. Isso equivale a dizer que não se pode falar em narrativa autofundadora, tanto mais porque a história do "Eu" é iniciada por outros, e outros, ainda, a concluirão - não por acaso Paul Ricoeur observa que "minha morte pertencerá à narrativa daqueles que a mim sobreviverão" (RICOEUR, 1990, p. 189). 
Deve-se, por isso mesmo, fazer a hipótese de que as diversas formas da narrativa de si em geral, e aquela de Annie Ernaux em particular, são manifestação de uma potência inventiva cuja condição, contrariamente à permanência de uma identidade, é justamente como que uma traição da própria subjetividade. $\mathrm{O}$ "Eu", opaco a si mesmo, só pode ser "Eu" porque se despossui de si e entra em relação com o Outro. Se é possível admitir que as narrativas de si são tecidas pelo trabalho de um "si" sobre "si", é inegável que tal trabalho evacua uma identidade perfeitamente definida para acolher uma emergência modulada, isto é, infletida, por um lado, pela memória, pelas histórias familiares, fraternais, sociais, políticas, dentre outras; e, por outro, pela linguagem mesma, que movimenta todas essas memórias, todas essas histórias.

Escrever (sobre)

os afetos: a escrita íntima de Annie Ernaux

\section{O Eu é o Diverso, em linguagem}

"É na linguagem e pela linguagem que o homem se constitui como sujeito" (BENVENISTE, 1988, p. 286). A afirmação é das mais relevantes e permite afirmar que a atividade de linguagem confunde-se com o próprio exercício da invenção de si, exercício que se revela a um tempo experiência intersubjetiva e transubjetiva. Nesse sentido, importa abrir aqui um excursus que relembrará algumas relevantes contribuições de Émile Benveniste para a compreensão da subjetividade, na linguagem e em linguagem, e que dará a perceber o quanto a escrita de si em Annie Ernaux está imersa em jogos discursivos que, sim, é inegável, têm o ego em seu centro, mas um ego em eterno movimento, em deslocamento incansável em direção ao outro.

Importa, antes de tudo, assinalar que a

\footnotetext{
subjetividade [...] não é mais que a emergência no ser de uma propriedade fundamental da linguagem. É 'ego' que diz ego. Encontramos aí o fundamento da "subjetividade" que se determina pelo status linguístico da "pessoa" (BENVENISTE, 1988, p. 286, grifos do autor).
}

O que quer dizer que toda subjetividade só se constitui como tal se se expressa graças à linguagem e na linguagem. O Eu é, por conseguinte, instância linguística ou, se se preferir, discursiva; é a linguagem que torna ego um sujeito. Ele nada é fora da linguagem. 
A linguagem é, pois, a possibilidade da subjetividade, pelo fato de contar sempre com as formas linguísticas apropriadas à sua expressão; e o discurso provoca a emergência da subjetividade [...] (BENVENISTE, 1988, p. 289).

Percebe-se, por isso mesmo, que todo ato de escritura é, em seu início, e de modo incontornável, uma autoenunciação, pois aquele que "escreve se enuncia ao escrever" (BENVENISTE, 1989, p. 90). Entretanto, Leila esse mesmo ato de escritura, se pensado em regime das escritas de si, de Aguiar escaparia de sua origem autotélica e ganharia os registros da alocução,

Costa no sentido em que, ao se enunciar, faz com que "os indivíduos se enunciem" (BENVENISTE, 1989, p. 90). Eis então o eu diante do tu, que pode 140 ser o si, mas igualmente o outro. Só se é em "contraste", em "reciprocidade", em "diálogo", como bem afirma Benveniste:

A consciência de si mesmo só é possível se experimentada por contraste. Eu não emprego eu a não ser dirigindo-me a alguém, que será na minha alocução um tu. Essa condição de diálogo é que é constitutiva da pessoa, pois implica em reciprocidade - que eu me torne tu na alocução daquele que por sua vez se designa por eu [...]. Por isso, eu propõe outra pessoa, aquela que, sendo embora exterior a "mim", torna-se o meu eco - ao qual digo tu e que me diz tu (BENVENISTE, 1988, p. 284-291, grifos do autor).

É-se, assim, identidade linguística ou, para falar como Benveniste, "instância de discurso". Ou, em regime narrativo, e segundo os termos de Paul Ricoeur, identidade/instância narrativa, expressão mesma da linguagem.

Importa ainda observar que, segundo Benveniste, "o fundamento mesmo da subjetividade está no exercício da língua” (1988, p. 286). O que significa dizer - e, de certo modo, reforçar tudo o que vem sendo afirmado - que toda construção da subjetividade passa necessariamente pela apropriação que o sujeito faz da língua; ao dela se apropriar, ele pode, então, designar-se como eu. E no ato mesmo dessa designação de um eu se organiza imediatamente toda uma rede enunciativa que 
implanta o outro diante de si, qualquer que seja o grau de presença que ele atribua a este outro. Toda enunciação é, explicita ou implicitamente, uma alocução, ela postula um alocutário (BENVENISTE, 1989, p. 84, grifos do autor).

O impacto de tal postulação é dos mais relevantes se considerarmos que as redes de afetos que se constroem nas escritas de si não prescindem precisamente do motus da relação; dessa relação que, pensada por Benveniste, supõe a presença de um "parceiro, seja este real ou imaginado, individual ou coletivo" (BENVENISTE, 1989, p. 87). As redes de afetos são tramas construídas sob a égide de um vai e vem entre o protagonista direto da enunciação e outros tantos que se insinuam em enunciações laterais, indiretas. É inegável que o Eu é o Outro, ou, se se

Escrever (sobre) os afetos: a escrita íntima de Annie Ernaux preferir, o Diverso. E sempre em linguagem. Tanto mais porque a pertença de todos ao real passa pela enunciação. De Si, do sujeito, do Outro, de Todos, do Mundo. E dos afetos.

\section{Sou Eu graças ao Outro, externo a Mim}

Em 1993, Annie Ernaux publica Journal du dehors ${ }^{1}$. Sua epígrafe é das mais reveladoras. Uma passagem emprestada de Jean-Jacques Rousseau dá o tom e o(s) sentido(s) de tudo quanto se expõe na exterioridade de uma figura feminina ${ }^{2}$ que transcreve cenas, palavras ouvidas nos trens de subúrbio, dans les hypermarchés, au Centre Commercial de la Ville Nouvelle où [elle] habite (ERNAUX, 1993, quarta-capa) ${ }^{3}$. Leia-se, pois, a significativa passagem de Rousseau: Notre vrai moi n'est pas tout entier

1 Antes desse texto, Annie Ernaux (1940-) já havia publicado, entre outros, Les armoires vides (1974), Ce qu'il disent ou rien (1977), La femme gelée (1981), La place (1984) - que recebeu um dos célebres prêmios literários franceses, o Prix Renaudot -, Une femme (1987), Passion simple (1991). Escritora profícua, publica após Journal de dehors, entre outros, Je ne suis pas sortie de ma nuit (1996), La honte (1997), La vie extérieure (2000), Les années (2007) - considerada como uma autobiographie impersonnelle (autobiografia impessoal) - e, mais recentemente, Mémoire de fille (2016). La place, Une femme e Journal du dehors, como se verá na sequência, inscrevem-se naquela trama narrativa de afetos de que se fala neste artigo.

2 Importa observar o movimento linguístico mesmo do aparecer dessa figura feminina: o "je" que assume a narrativa parece se esvanecer na descrição de atos e fatos relativos ao outro. Isso é tanto mais verdade que o emprego do pronome pessoal em primeira pessoa revela-se como um problema enunciativo, quiçá sem resolução: [...] je m'expose à toutes sortes de remarques que ne provoqueraient pas 'elle s'est demandé si l'homme à qui elle était en train de parler n'était pas celui-là'. La troisième personne, il/elle, c'est toujours l'autre, qui peut bien agir comme il veut [...]'Je' fait honte au lecteur/[...] "exponho-me a todo tipo de observação que não aconteceria se dissesse "ela se perguntou se o homem a quem falava não era aquele'. A terceira pessoa, ele/ela, é sempre o outro, que pode agir como quiser [...] 'Eu” envergonha ao leitor" ; ERNAUX, 1993, pp. 18-19, tradução minha). Não por acaso, em entrevistas com frequência concedidas, Annie Ernaux diz praticar uma écriture impersonnelle (escritura impessoal).

3 "Nos hipermercados, no Centro Comercial da Cidade Nova onde [ela] mora" (Tradução minha). 
en nous ${ }^{4}$. O que significaria que nosso verdadeiro eu está, em parte, fora de nós e que a essa exterioridade cumpriria, de certa maneira, dar a descobrir o íntimo. Esse, aliás, é o mote do Journal du dehors, onde cada um carrega a vida de todos - como se verá mais adiante.

Journal du dehors, pois. Jornal íntimo, inicialmente, isto é, narrativa cujo intento, em geral, é aquele figurar um Eu verdadeiro que, graças à mediação da linguagem (e da escrita), deve tornar-se verdadeiro para parecer precisamente verdadeiro. Antes de tudo, permita-se observar, Leila de modo lateral, que o termo "jornal” (journal, em francês) é aqui conde Aguiar vocado no sentido de journal intime - que, em português, costuma ser traduzido por "diário", embora não houvesse, diga-se de passagem, problema teórico algum em se adotar o termo "jornal íntimo". Trata-se, pois, de texto em modo narrativo, modo narrativo, aliás, impuro, ambíguo - ambiguidade que se percebe, em língua francesa, até mesmo no registro terminológico, que inscreve no mesmo bojo journal, carnets, cahiers, notes, réflexions... Narração, por isso mesmo, bastante híbrida, no sentido em que ali se esboça forte oscilação entre o real e o imaginário. Por conseguinte, reconhece-se no jornal íntimo uma maneira de ser/estar-no-mundo que interpela o exterior para se (re)conhecer. Não surpreende, pois, que o jornal íntimo seja atravessado a um tempo pela verdade e pela vontade de verdade ${ }^{5}$.

É o que parece insinuar a própria voz narrativa feminina de Journal du dehors quando afirma que ela cherche toujours les signes de la litté-

4 A epígrafe de La Place emprestada de Rousseau omite a primeira parte do que se lê em Rousseau juge de Jean-Jacques - e que está em perfeita consonância com o que já disse -: Notre plus douce existence est relative et collective, et notre vrai moi n'est pas entier en nous/ Nossa mais doce existência é relativa e coletiva , e nosso verdadeiro eu não está inteiramente em nós" (ROUSSEAU, 1962, p. 156, tradução minha).

5 Não é demasiado relembrar, na contracorrente da positividade que aqui se reconhece ao jornal íntimo em relação às narrativas de Ernaux, que Maurice Blanchot enuncia um juízo todo negativo sobre esse modo. Ele faz pairar sobre o gênero jornal íntimo a terrível dúvida sobre se ali se reconheceria, ou não, uma escritura literária. Em 0 espaço literário, no capítulo intitulado “A solidão essencial/Recurso ao diário", censura-se a prática do diário - esse é o termo adotado pelas traduções brasileiras - porque ela permitiria a um escritor se aproximar de um destino pessoal, de preservar certa pessoalidade de que, como se sabe, a obra blanchotiana procura se desembaraçar a cada linha e a cada reflexão. Blanchot ali pensa que a obra literária deve colocar em questão e ameaçar a relação pessoal - o que significa negar ao diário a qualidade de obra literária. Em o livro por vir, no capítulo intitulado "O diário íntimo e a narrativa", Blanchot assinala que escrever um diário é atividade das mais insignificantes e, por isso mesmo, destituída de viés poético. Tanto mais porque, para ele, escrever supõe a perda de identidade daquele que se conta e que conta algo que aconteceu em uma fragmentação infinita. Não por acaso, Blanchot afirma que não há o "menor interesse em pensar em si, em voltar-se para si mesmo" (2004, p. 274); o que significaria dizer, em perspectiva blanchotiana, que o gênero do diário é gênero malogrado. E gênero tanto mais malogrado porque seu objetivo, aquele de se conhecer a si mesmo, é impossível. Em suma, "escrever é romper com o laço que une a palavra a mim mesmo" (BLANCHOT, 1987, p. 16). 
rature dans la réalité (ERNAUX, 1993, p. 46)6. Jornal íntimo, ainda, pois que o movimento empreendido pela narradora de surpreender cenas, gestos, palavras percebidos a seu redor em lugares do cotidiano é justamente aquele de uma escrita de si cujo modo de conviver com o outro e com o mundo passa pela (a)notação de tudo quanto põe em cena a consciência do sujeito.

Jornal íntimo, sim. Mas jornal íntimo do fora, da exterioridade, do que não está justamente no sujeito. Se o gênero "jornal íntimo" revela-se geralmente escrita do intimus, o Journal du dehors é sobretudo escrita que parte do externos, locado por isso mesmo no extimus, para afinal ganhar o intimus e dar a compreendê-lo ${ }^{7}$. Sentada, assim, em um banco de um vagão de trem suburbano, a figura feminina, que, em seu gesto de percepção do real, transcreve o que vê e o que ouve a seu redor, procura

Escrever (sobre) os afetos: a escrita íntima de Annie Ernaux se descobrir e se compreender graças ao Outro. Não se é senão porque se é igualmente outro além de si. Não haveria aí, por isso mesmo, certa despossessão do sujeito? Ou, como quer André Malraux em Lazare, um je-sans-moi, une vie sans identité (1974, p. 143) ${ }^{8}$ ? Ou, ainda, segundo Jean-Michel Maulpoix em L'écrivain imaginaire (1994, p. 30), um homme dont quelqu'un s'en est allé '? Vida entregue aos encontros e desencontros daquela figura feminina que, em posição de espectador, dá-se o exercício do testemunho no registro mesmo da heterogeneidade da vida - vida a um tempo, já se percebeu, coletiva e íntima; vida que descobre le propre corps qui regarde ailleurs (MAULPOIX, 1994, p. 28) ${ }^{10}$. É como ela diz:

noter les gestes, les attitudes, les paroles de gens que je rencontre me donne l'illusion d'être proche d'eux. Je ne leur parle pas, je les regarde et les écoute seulement (ERNAUX, 1993, p. 36) ${ }^{11}$.

\footnotetext{
6 "busca sempre os sinais da literatura na realidade" (Tradução minha).

7 Importa observar que Annie Ernaux afirma que seu Journal du dehors poderia ser classificado, antes, como um "jornal pessoal": "journal impersonnel où il est question de la réalité quotidienne, urbaine, collective" / "jornal impessoal onde é caso da realidade cotidiana, urbana, coletiva” (apud JUNGERMAN, 2011, p. 13, tradução minha).

8 "eu-sem-mim, uma vida sem identidade" (Tradução minha).

9 "um homem do qual alguém se foi" (Tradução minha). Em Maulpoix, esse homem é exatamente o "escritor".

10 "o próprio corpo que olha alhures" (Tradução minha).

11 “Anotar os gestos, as atitudes, as palavras de pessoas que eu encontro me dá a impressão de estar próxima delas. Não falo com elas, simplesmente as olho e as ouço” (Tradução minha).
} 
O Eu nasce, por isso mesmo, dos afetos percebidos naquele Outro-além-de-si. Mais do que próxima dele, o Eu nele se reconhece, torna-se Ele; eu diferente de Si, mas igual ao Outro ${ }^{12}$ :

Peut-être que je cherche quelque chose sur moi à travers eux, leurs façons de se tenir, leurs conversations. (Souvent, 'pourquoi ne suis-je pas cette femme ?' assise devant moi dans le métro, etc.) (ERNAUX, 1993, p. 37) ${ }^{13}$.

Leila de Aguiar

Costa

Constituição de um eu-sem-mim. Despossuído de si que está, entretanto, em todos os lugares, em todos os corpos, em todos os gestos, em todas as falas. Em todos os afetos de outrem que são como que roubados para melhor serem incorporados. "Eu" cuja identidade é identidade discursiva e identidade narrativa, que só tem razão de ser porque se põe a escrever e a registrar escrituralmente o que vê. "Eu" que é, por isso mesmo, como que um "eu postiço", como diria Fernando Pessoa ${ }^{14}$. Profusão de "Eus" postiços que se insinua nessa mesma rede de sujeitos. Não propriamente um "Eu", mas uma confusão de "não-eus".

\footnotetext{
Un jeune homme aux jambes fortes, grand, la bouche épaisse, est assis dans le R.E.R. sur un siège en bordure de l'allée centrale. De l'autre côté, une femme avec un petit garçon de deux ou trois ans sur les genoux, qui regarde autour de lui, comme suffoqué d'étonnement, puis demande 'comment le monsieur ferme les portes'. Sans doute la première fois qu'il prend le R.E.R. L'un et l'autre, le jeune homme et l'enfant, me reportent à des moments de ma vie. L'année du bac, en mai, lorsque D., grand, lèvres fortes, comme le garçon là-bas, m'attendait à la sortie des cours, près de la poste. Plus tard, le temps où mes fils étaient petits et découvraient le monde.
}

12 Tal postulação ganha ainda maior sentido quando se pensa, com Deleuze, que os afectos são "des devenirs qui débordent celui qui passe par eux"/“devires que transbordam aquele que passa por eles" (DELEUZE, 2003, p. 182, tradução minha).

13 "Talvez eu busque algo sobre mim através deles, de suas maneiras de se apresentar, suas conversas (com frequência, 'por que não sou esta mulher'? sentada diante de mim no metrô, etc.)” (Tradução minha).

14 "Eu sinto-me vários seres. Sinto-me viver vidas alhures, em mim, incompletamente, como se o meu ser participasse de todos os homens, incompletamente de cada, por uma suma de não-eus sintetizados num eu postiço" (PESSOA, 1998, p. 81). 
Releve-se da passagem, para além do evidente traço descritivo de seu início - que coloca o leitor precisamente diante do jovem rapaz, da mulher e da criança em seu colo, como se ele próprio participasse da cena -, a confusão desejada entre o que está fora de Si e o que seria o Eu. A história do sujeito não se origina nele próprio, mas, antes, nas histórias diversas de outros tantos "Eus" que são a um tempo ipse e alter e que mutuamente e reciprocamente trabalham na constituição mesma de cada pessoalidade, de cada subjetividade. Existências, vidas que se entrecruzam na exterioridade que, por conseguinte, conforma uma história privada daquele sujeito, semelhante no interior mesmo da dessemelhança. Je sais que dans les notations de cette vie extérieure, plus que dans un journal intime, se dessinent ma propre histoire et les figures de ma ressemblance (ERNAUX, 2000, quarta-capa) ${ }^{15}$.

Escrever (sobre)

os afetos:

a escrita íntima

de Annie Ernaux

Existências, vidas que atravessam umas às outras. É saborosa a imagem convocada pela voz narrativa a esse respeito; saborosa porque dá protagonismo ao corpo, corpo público, comunitário, desprovido de pessoalidade; corpo que é um e vários a um só tempo e que se modela em função do que lhe é solicitado: Je suis traversée par les gens, leur existence, comme une putain (ERNAUX, 1993, p. 69) ${ }^{16}$.

Existências e vidas que se entrecruzam e se atravessam no que a voz feminina narrativa diz ser tão somente "instantes" e, sobretudo, "encontros". E, ainda, "etnotexto"17 - cuja definição a voz narrativa toma de maneira um tanto livre, pois que nele reconhece uma diversidade de discursos inscritos na cultura oral de uma comunidade de textos "compostos" por outros. Etnotexto, pois. Jornal íntimo do fora - jornal íntimo, mas impessoal - que, afinal, é habitado por Todos.

\section{Somos Todos, mas não somos mais "Eu" ou "Nós"}

Em Journal du dehors, a voz feminina narrativa dissera reencontrar gestos e frases da mãe em uma mulher que esperava sua vez em um caixa

\footnotetext{
15 "Sei que nas anotações desta vida exterior, mais do que em um jornal íntimo, desenham-se minha própria história e as figuras de minha semelhança” (Tradução minha).

16 "Sou atravessada pelas pessoas, por sua existência, como uma puta" (Tradução minha).

17 "Par ethnotextes, il faut entendre avant tout des textes oraux, littéraires ou non, dialectaux ou français, ayant une valeur ethnologique, historique, linguistique. Mais la notion d'ethnotexte s'applique aussi aux sources écrites de textes oraux ou à leurs versions écrites eventuelles" (JOUTARD, Philippe. Un projet régional de recherche sur les ethnotextes)/"Por etnotextos, é preciso compreender todo texto oral, literário ou não, dialetal ou francês, que tenham valor etnológico, histórico, linguístico. Mas a noção de etnotexto aplica-se igualmente às fontes escritas de textos orais ou às suas versão escritas eventuais". In: Annales, no. 25(1), p. 176, 1980, tradução minha).
} 
de supermercado. Uma vez mais o fora a se enunciar. Pois que o sujeito, para se construir como subjetividade, deve-se deixar habitar por tudo quanto pode constituí-lo. Reafirme-se que as narrativas intituladas La place, Une femme e Journal du dehors são paradigmáticas de uma escrita do(s) afeto(s) que põe em relação a subjetividade e a outridade graças ao trabalho com a linguagem ${ }^{18}$.

Alguns anos antes da publicação do Journal du dehors, Annie Ernaux oferece ao público a narrativa La place (1983), em que o pai torna-se protagonista. Para começar, então, o pai - a fim de pôr em cena a relação entre filha e pai. Esse pai que falece dois meses após o sucesso de sua filha em um exame que a torna professora. Esse pai que, inicialmente operário e em seguida pequeno comerciante, desejava que sua filha fosse melhor que ele. Graças aos estudos. Aos livros e à música de que ele não tinha necessidade alguma para viver. Esse pai para o qual é fundamental (re)encontrar o (seu) lugar - importa observar que a narrativa intitula-se La place. Lugar do pai. Que sabe bem seu lugar. Que sua filha precisa compreender para enfim compreender qual é o seu - pois que seu lugar passa pela descoberta do lugar do outro. Entretanto, para ali chegar, é preciso passar por outros lugares, por aquele etnotexto de que se falou, por aquela travessia dos corpos, por aquele entrecruzamento entre os sujeitos. (Des)figurados. Anônimos. Iguais a todos, iguais ao pai - aos pais. E, no interstício, emergirão os afetos tramados entre pai(s) e filha(s).

C'est dans la manière dont les gens s'assoient et s'ennuient dans les salles d'attente, interpellent leurs enfants, font au revoir sur les quais de gare que j'ai cherché la figure de mon père. J'ai retrouvé dans des êtres anonymes rencontrés n'importe où, porteurs à leur insu des signes de force ou d'humiliation, la réalité oubliée de sa condition (ERNAUX, 1983, p. 100-101) ${ }^{19}$.

Rede de afetos que começa a ser narrada a partir da morte do pai. As páginas iniciais de La place recorrem a uma descrição da morte quase que meramente objetiva. Entretanto, em filigrana, estas primei-

18 Como diria Paul Auster, “a linguagem não é a verdade. A linguagem é nossa maneira de existir no universo" (citado por ERNAUX, 1997, epígrafe).

19 "É no modo com que as pessoas se sentam ou se entediam nas salas de espera, com que interpelam seus filhos, com que se dão adeus nas plataformas de trem que busquei a figura de meu pai. Redescobri em seres anônimos encontrados em qualquer lugar, que carregam contra sua vontade sinais de força ou de humilhação, a realidade esquecida de sua condição" (Tradução minha). 
ras páginas são como um exutório que busca afastar os fantasmas da desfiguração e, por isso mesmo, da perda das origens. Pois que ao ver a face morta do pai a filha não mais reconhece a face do próprio pai. Não é mais o pai. As origens assim se esvaecem.

En quelques heures, la figure de mon père est devenue méconnaissable. Vers la fin de l'après-midi, je me suis trouvée seule dans la chambre. Le soleil glissait à travers les persiennes sur le linoléum. Ce n'était plus mon père. Le nez avait pris toute la place dans la figure creusée. Dans son costume bleu sombre lâche autour du corps, il ressemblait à un oiseau couché. Son visage d'homme aux yeux grands ouverts et fixes de l'heure suivant sa mort avait déjà disparu. Même celui-là, je ne le reverrais plus (ERNAUX, 1983, p. 16) ${ }^{20}$.

Escrever (sobre) os afetos: a escrita íntima de Annie Ernaux

Escrever, então, sobre o pai a partir de sua morte é como que oferecer a ele um jazigo, aquele consignado pela escritura. Nada de surpreendente aqui, pois que a morte em geral assombra as escritas de si que, ao final, fazem desaparecer o corpo - aqui desfigurado - para fazê-lo renascer transfigurado, como corpus. La place seria por isso mesmo a face mais verdadeira do pai. Mas como dizê-la? Porque, segundo a voz feminina da filha, en m'efforçant de révéler la trame significative d'une vie dans un ensemble de faits et de choix, j'ai l'impression de perdre au fur et à mesure la figure particulière de mon père (ERNAUX, 1983, p.45) ${ }^{21}$. Como então escrevê-la, sem trai-la ${ }^{22}$ ? Inscrevendo-se em uma memória familiar, abdicando do individual e, sobretudo, negando-se como "Eu", como sujeito-literário ${ }^{23}$. Para tanto, a voz feminina assim o revela, adota-se o partido do que denomina uma écriture plate (ERNAUX, 1983, p. 24), escritura sem poesia, sem emoção,

20 "Em algumas horas, a fisionomia de meu pai se tornou irreconhecível. Por volta do final da tarde, encontrei-me só no quarto. $\mathrm{O}$ sol passava através das persianas sobre o linóleo. Não era mais meu pai. O nariz havia invadido toda a fisionomia sulcada. Em seu terno azul escuro solto em torno do corpo, ele se parecia com um pássaro deitado. Seu rosto de homem, com os olhos muito abertos e fixos, uma hora após sua morte, havia desaparecido. Mesmo esse eu não reverei mais" (Tradução minha).

21 "Esforçando para revelar a trama significativa de uma vida em um conjunto de fatos e de escolhas, tenho a impressão de perder pouco a pouco a fisionomia particular de meu pai" (Tradução minha).

22 Vale observar que a epígrafe do volume é emprestada de Jean Genet: "Je hasarde une explication: écrire c'est le dernier recours quand on a trahi"/ "Arrisco uma explicação: escrever é o último recurso quando traímos" (ERNAUX, 1983 p. 9; tradução minha).

23 Em La Place, a voz feminina dirá que, para escrever (sobre) a mãe, era preciso colocar-se abaixo da literatura... 
au plus près des mots et des phrases entendues [...] parce que ces mots et ces phrases disent les limites ou la couleur du monde où vécut mon père, où j'ai vécu. Et l'on n'y prenait jamais un mot pour autre (ERNAUX, 1983, p. 46) ${ }^{24}$.

Nessa escritura que se quer fiel ao mundo das origens, não há lugar para os segundos sentidos, para os duplos sentidos, para a polissemia da linguagem. Tanto mais porque, para o pai, o "espiritual" era algo

Leila "inútil". Não por acaso, os afetos experimentados entre pai e filha code Aguiar meçam a se esvanecer no momento em que a progenitura se afasta das

Costa origens graças ao domínio culto que fará da linguagem ${ }^{25}$. Entretanto, o exercício de rememoração dos afetos que unem pai e filha passa pela 148 linguagem. Mesmo que, para deles dar conta, a voz narrativa recorra àquela écriture plate, o dilema ainda a assombra. Pois que ao escrever sobre o pai, ao descrevê-lo e ao descrever o par Pai-Filha, a escritura provoca a perda da própria figura do pai. La place seria então o malogro da escritura de si uma vez que não logra apreender o Outro, mesmo que naqueles seres anônimos reencontrados em quaisquer lugares. Ainda mais porque em certo momento de La place o "Eu" descobre que não faz mais parte de um "Nós".

\section{Não sou Eu, mas somos todos afetos}

À maneira do que ocorrera com La place, Une femme (1987) abre-se com o anúncio da morte da mãe - que, importa dizê-lo, em uma pungente mise en abyme, morre em decorrência da doença que destrói toda memória, a doença de Alzheimer. Nesse sentido, não seria equivocado afirmar que, no interior mesmo de uma escrita de si que busca reconstruir a própria subjetividade e recuperar os laços afetivos que a uniam àquele "Nós" graças às reminiscências, inscreve-se a morte mesma da memória. Entretanto, trata-se de reencontrar o que já se perdeu. O projeto aqui é, pois, aquele de reconstrução de certa genealogia familiar que enraizaria o "Eu" em uma trama do coletivo, salvando-o da solidão e da armadilha do individual. É o que se buscará, em Une femme, graças à linguagem e à escritura:

24 "o mais perto possível das palavras e das frases ouvidas [...], porque essas palavras e essas frases dizem os limites ou a cor do mundo em que viveu meu pai, em que eu vivi. E nunca confundíamos o sentido de uma palavra com outro" (Tradução minha).

25 "Tout ce qui touche au langage est dans mon souvenir motif de rancoeur et de chicanes douloureuses [...]"/ "Tudo o que diz respeito à linguagem é, em minha lembrança, motivo de rancor e de chicanas dolorosas" (ERNAUX, 1983, p. 64, tradução minha). 
Il fallait que ma mère, née dans un milieu dominé, dont elle a voulu sortir, devienne histoire, pour que je me sente moins seule et factice dans le monde dominant des mots et des idées où, selon son désir, je suis passée (ERNAUX, 1987, p. 43) ${ }^{26}$.

Somente quando aquela que não tinha "história" (ERNAUX, 1987, p. 22) torna-se "história" (ERNAUX, 1987, p. 43) é possível torná-la memorável. É, pois, graças à linguagem, à apropriação do mundo e do outro pela linguagem, que a mãe pode existir: Il me semble maintenant que j'écris sur ma mère pour, à mon tour, la mettre au monde (ERNAUX, 1987, p. 43) ${ }^{27}$. Ainda: é porque a mãe se faz história e ganha uma história que a filha pode ser filha - ou, se se quiser emprestar

Escrever (sobre)

os afetos: a escrita íntima de Annie Ernaux os termos de Gilles Deleuze, devir-filha, tanto mais porque um devir está inexoravelmente ligado a outro devir; por isso mesmo, o devir-mãe encadeia-se ao devir-filha graças ao "escrever" 28 . Mãe que se torna mãe porque alguém a escreve; filha que se torna filha, não porque escreveu sobre a mãe, mas porque escreveu a mã $e^{29}$. Não ecoaria nessa voz feminina de Ernaux precisamente a reflexão de Deleuze que afirma que o escrever é um devir? -

Ao escrever sempre se dá escritura a quem não tem, mas estes dão à escritura um devir sem o qual ela não existiria, sem o qual ela seria pura redundância a serviço das potências estabelecidas (DELEUZE, 1998, p. 36).

Devir-mãe/devir-filha que não são da ordem do individual, do subjetivo. Antes, e é por isso que os afetos circulam e se entrecruzam, eles inscrevem-se à la jointure du familier et du social, du mythe et

26 "Era preciso que minha mãe, nascida em um meio dominado, do qual ela desejou sair, se tornasse história, para que eu me sinta menos só e mais factível no mundo dominante das palavras e das ideias ao qual, segundo seu desejo, eu adentrei" (Tradução minha).

27 "Parece-me agora que escrevo sobre minha mãe para, agora eu, colocá-la no mundo" (Tradução minha).

28 "Escrever é um caso de devir, sempre inacabado, sempre em via de fazer-se, e que extravasa qualquer matéria vivível ou vivida. É um processo, ou seja, uma passagem de Vida que atravessa o vivível e o vivido. A escrita é inseparável do devir: ao escrever, estamos num devir-mulher, num devir-animal ou vegetal, num devir-molécula, até num devir-imperceptível. Esses devires encadeiam-se uns aos outros [...]" (DELEUZE, 1997, p. 11).

29 “Escrever é tornar-se [...] É tornar-se outra coisa" (DELEUZE, 1998, p. 35). 
de l'histoire (ERNAUX, 1987, p. 22) ${ }^{30}$. Não por acaso, Une femme, texto que a crítica considera como pertencente à autoficção, nega-se como tal: Ceci n'est pas une biographie, ni un roman naturellement, peut-être quelque chose entre la littérature, la sociologie et l'histoire (ERNAUX, 1987, p. 22) ${ }^{31}$. E não poderia ser de outro modo. Segundo Annie Ernaux, escrever é estar fora de si, e essa exterioridade é garantia de encontro amoroso com o Outro. É necessário, por isso mesmo, adotar o que ela denomina a autosociobiographie, que funda o sujeito graças

Leila a uma relação de si com aquele Outro. Seja como for, a trama dos de Aguiar

Costa afetos instituída assim em diálogo depende exclusivamente da linguagem e da escritura: je place toujours en premier la vérité du livre que je suis en train d'écrire: c'est lui, sa forme, qui commande ${ }^{32}$. Escritura, pois, (im)pessoal dos afetos ${ }^{33}$.

\section{Memória(s)}

Diga-se então: a escrita íntima de Annie Ernaux propõe-se não a "escrever minha vida" ou, mesmo, "escrever uma vida" mas, antes, "escrever a vida" 34 - aliás, Ecrire la vie é o título de uma de suas obras, publicada em 2011. O que equivale a dizer que a ela interessa se prendre non comme sujet mais comme objet pour découvrir des réalités plus générales ${ }^{35}$, mesmo que se saiba que

30 "na junção do familiar e do social, do mito e da história" (Tradução minha).

31 "Isso não é um biografia, nem naturalmente um romance, talvez algo entre a literatura, a sociologia e a história” (Tradução minha).

32 "coloco sempre em primeiro lugar a verdade do livro que estou escrevendo: é ele, sua forma, que comanda" (Tradução minha).

33 Leia-se, com proveito, sobre tal impessoalidade advinda com a escritura, o que diz Annie Ernaux, em entrevista concedida a Nathalie Jungerman: "On entre dans une forme et quand c'est écrit, ce n'est plus à soi... L'écriture est tournée vers les autres. Elle est la recherche de vérité hors de soi"/“Entra-se em uma forma e quando está escrito, não pertence mais a si... A escritura está voltada para os outros. Ela é a busca de verdade fora de si" (apud JUNGERMAN, 2011, p. 14, tradução minha).

34 "Écrire la vie. Non pas ma vie, ni sa vie, ni même une vie. La vie, avec ses contenus qui sont les mêmes pour tous mais que l’on éprouve de façon individuelle : le corps, léducation, l,appartenance et la condition sexuelles, la «trajectoire sociale, liexistence des autres, la maladie, le deuil. Je n'ai pas cherché à m'écrire, à faire cuvre de ma vie : je me suis servie d'elle, des événements, généralement ordinaires, qui l'ont traversée, des situations et des sentiments qu'il m'a été donné de connaître, comme d'une matière à explorer pour saisir et mettre au jour quelque chose de l'ordre d'une vérité sensible"/ Escrever a vida. Não minha vida, nem sua vida, nem mesmo uma vida. A vida, com seus conteúdos que são os mesmos para todos, mas que experimentamos de modo individual: o corpo, a educação, a pertença e a condição sexuais, a trajetória social, a existência dos outros, a doença, o luto. Não busquei me escrever, fazer obra de minha vida: servi-me dela, dos acontecimentos, geralmente comuns, que a atravessaram, situações e sentimentos que me foram dados a conhecer, como se fosse uma matéria a explorar para apreender e dar à luz alguma coisa da ordem de uma verdade sensível (ERNAUX, 2011, p. 7-8, tradução minha).

35 "assumir-se não como sujeito, mas como objeto para descobrir realidades mais gerais" (Tradução minha). 
on part toujours de soi [...] et chacun est la première mesure du monde mais tout dépend du projet, fermé sur soi ou ouvert sur l'inconnue que l'écriture a pour charge, alors, d'explorer (apud JUNGERMAN, 2011, p. 8) ${ }^{36}$.

Não há, por isso mesmo, "memória de si" senão em sua pertença ao mundo que a cerca, capaz de dar conta - e rendre compte, nos termos de Ernaux, significa assumir une éthique à la fois de vérité et de recherche de la vérité (FORT, 2015, p. 8) $)^{37}$ - do Eu, do Outro e dos afetos que mobilizam a todos e instaura a convivência entre todos. A(s) escrita(s) de Annie Ernaux, mesmo que íntimas, assumem certa distância precisamente em relação ao intimus do sujeito que as escreEscrever (sobre) os afetos: a escrita íntima de Annie Ernaux ve - écriture distanciée diz ela a respeito, por exemplo, de La place. Para Ernaux, o íntimo não é restritivo, pois l'intime est d'une certaine manière ce qu'il y a de plus partagé puisque ce sont justement des choses qui arrivent à tout le monde (apud JUNGERMAN, 2011, p. 13) ${ }^{38}$. Não surpreende assim que Ernaux atribua a tal termo (e à noção) aquele matiz ligado ao social que, nesse sentido, acaba por evacuar a escritura de todo egocentrismo:

Est-ce qu'il y a vraiment un intime ? Dans l'intime, quantité de choses relèvent du social, de l'historique. Un moi pur, où les autres, les lois, l'histoire, ne seraient pas présents, est inconcevable. Par exemple, dans le sexuel, il y a ce qui est permis ou pas permis à telle ou telle époque, ce qu'on va transgresser et qui renvoie donc à une loi extérieure à soi, au discours en usage, au monde social en général. Je sais que l'on m’a souvent classée parmi les 'écrivains de l'intime' mais je récuse cette définition qui prend surtout en compte le « je » de l'auteur comme objet du texte et non la façon d'écrire, qui peut être objective et non autocentrée (apud JUNGERMAN, 2011, p. 13) ${ }^{39}$.

\footnotetext{
36 "Parte-se sempre de si [...] e cada um é a primeira medida do mundo. Mas tudo depende do projeto, fechado sobre si ou aberto para o desconhecido que a escritura tem por função, então, explorar" (Tradução minha).

37 "uma ética a um tempo de verdade e de busca da verdade" (Tradução minha).

38 "o íntimo é, de certa maneira, aquilo que é mais partilhado pois que são justamente coisas que acontecem com todo mundo" (Tradução minha).

39 "Há efetivamente um íntimo? No íntimo, muitas coisas dependem do social, do histórico. Um eu
} 
Que se possa concluir: não seria equivocado afinal assinalar que tal distância é distância incontornável para a (re)construção dos afetos, uma vez que ce qui compte, dans les livres, c'est ce qu'ils font advenir en soi et hors soi (apud FORT, 2015, p. 1) ${ }^{40}$. A escritura de Annie Ernaux, como ela mesma afirma, está voltada para o(s) outro(s), que nos habita(m) - e quiçá assombram. Voix traversée par les autres voix [...] (ERNAUX, 2011, p. 8) ${ }^{41}$.

Leila

de Aguiar

\section{REFERÊNCIAS}

Costa BENVENISTE, Émile. Da subjetividade na linguagem. Problemas de Linguística geral I. Traduzido por Maria da Glória Novak. Campinas: Pontes, 1988, p. 284-293.

Aparelho formal da enunciação. Problemas de Linguística geral II. Traduzido por Eduardo Guimarães. Campinas: Pontes, 1989, p. 81-92.

BLANCHOT, Maurice. O espaço literário. Traduzido por Álvaro Cabral. Rio de Janeiro: Rocco, 1987.

O livro por vir. Traduzido por Leyla Perrone-Moisés. São Paulo: Martins Fontes, 2004.

DELEUZE, Gilles. Crítica e clínica. Traduzido por Peter Pál Pelbart. São Paulo: Editora 34, 1997.

puro, onde os outros, as leis, a história, não estariam presentes, é inconcebível. Por exemplo, no sexual, há aquilo que é permitido ou não permitido em tal ou tal época, o que se vai transgredir e que reenvia, pois, a uma lei exterior a si, ao discurso em uso, ao mundo social em geral. Sei que frequentemente me classificaram dentre os 'escritores do íntimo', mas recuso esta definição, que leva em consideração, sobretudo, o 'eu' do autor como objeto do texto e não o modo de escrever, que pode ser objetivo e não autocentrado" (Tradução minha).

40 "o que conta, nos livros, é o que eles fazem acontecer em si e fora de si" (Tradução minha).

41 "Voz atravessada por outras vozes" (Tradução minha). Ernaux afirma, de modo bastante eloquente, que a escritura é, afinal, uma transformação do interior no exterior, do eu/do vivido naquilo que existe fora de si. Para ela, transformação confunde-se com transubstanciação: "Je sens l'écriture comme une transsubtantiation, comme la transformation de ce qui appartient au 'vécu', au 'moi', en quelque chose existant tout à fait en dehors de ma personne [...]. Mais cette transsubtantiation ne s'opère pas d'elle-même, elle est produite par l'écriture, la manière d'écrire, non en miroir du moi mais comme la recherche d'une vérité hors de soi"/ "Sinto a escritura como uma transubstanciação, como a transformação do que pertence ao 'vivido', ao 'eu', alguma coisa que existe completamente fora de minha pessoa [...]. Mas essa transubstanciação não se opera por ela mesma, ela é produzida pela escritura, pela maneira de escrever, não em espelho do eu mas como a busca de uma verdade fora de si" (ERNAUX, 2003, p. 102, tradução minha). 
Diálogos. Traduzido por Eloisa Araújo Ribeiro. São Paulo: Editora Escuta, 1998.

Pourparlers. Paris : Minuit, 2003.

ERNAUX, Annie. La place. Paris: Gallimard, 1983.

. Une femme. Paris: Gallimard, 1987.

Journal du dehors. Paris : Gallimard, 1993.

La vie extérieure. Paris : Gallimard, 2000.

L'écriture comme un couteau. Entretien avec Frédéric-Yves Jeannet. Paris : Stock, 2003.

Ecrire la vie. Paris : Gallimard, 2011.

FORT, Pierre-Louis. Entretien avec Pierre-Louis Fort. Annie Ernaux. Paris : Presses Universitaires de la Sorbonne, 2015. Disponível em: https://books.openedition.org/psn/178\#text. Acesso em : 30 de julho de 2018.

JOUTARD, Philippe. Un projet régional de recherche sur les ethnotextes. In : Annales, no. 25(1), p. 176-182, 1980.

JUNGERMAN, Nathalie. Entretien avec Annie Ernaux. Propos recueillis par Nathalie Jungerman. Florilettres, édition octobre 2011. Disponível em: http://www.fondationlaposte.org/florilettre/entretiens/ entretien-avec-annie-ernaux-propos-recueillis-par-nathalie-jungerman. Acesso em: 30 de julho de 2018.

MALRAUX, André. Lazare. Paris: Gallimard, 1974.

MAUPOIX, Jean-Michel. L'écrivain imaginaire. Paris: Gallimard, 1994.

PESSOA, Fernando. Obras em prosa. Cleonice Berardinelli (org.). Rio de Janeiro: Nova Aguilar, 1998.
Escrever (sobre) os afetos: a escrita íntima de Annie Ernaux 
RICOEUR, Paul. Soi-même comme un autre. Paris : Seuil, 1990.

ROUSSEAU, Jean-Jacques. Rousseau juge de Jean-Jacques. Paris : Armand Colin, 1962.

Recebido em fevereiro de 2018

Aceito em abril de 2018

Leila

de Aguiar

Costa

154 